\title{
Effects of Low-price Cosmetics Experience Factors on Satisfaction with Test Products
}

\author{
Sang Eun Lee \\ Department of Beauty Arts, Suwon Women's University, Suwon-si, Gyeonggi-do, Korea
}

Corresponding author: Sang Eun Lee, Department of Beauty Arts, Suwon Women's University, 72 Onjeong-ro, Gwonseon-gu, Suwon-si, Gyeonggi-do 16632, Korea Tel.: +82 312908374

Email: make-up1004@swc.ac.kr

Received August 31, 2016

Revised October 14, 2016

Accepted October 19, 2016

Published December 30, 2016

\begin{abstract}
Purpose: This study investigated the effects of a strategic experience module that differentiates low-price cosmetic brands with satisfied test products. Methods: Women who had previously visited a low-price cosmetics shop were collected through convenience sampling. The reliability of satisfaction was measured using Cronbach's $\alpha$. To measure the effects of low-price cosmetics experience factors on satisfaction with test products, correlation analysis and multiple regression analysis were conducted. Results: In terms of correlations between low-price cosmetics experience factors and satisfaction with test products, "act" was most correlated, followed by "relate", "think", "feel”, and "sense". In a low-price cosmetics experience, as "act", "relate", "sense", and "think" increased, satisfaction with test products improved. Conclusion: From this experience of factor-based marketing, the importance of promoting new service marketing in connection with diverse factors and establishing a brand image by offering consumers an opportunity to use products in person becomes evident.
\end{abstract}

Keywords: Experiential marketing, Satisfaction, Low-cost cosmetics, Experience factors, Cosmetics industry

\section{Introduction}

화장품 산업의 발전으로 인하여 제품의 특징에 대한 설명과 홍 보 등으로 나열하는 마케팅이 더 이상 소비자를 자극하지 못하는 상황에서 소비자의 감성과 이성을 자극하는 소비심리를 이용한 체 험 마케팅이 대두되고 있다.

저가화장품 브랜드는 저렴한 가격과 고가화장품 못지 않는 효과 적인 제품들을 내세우면서 소비자들의 인기를 끌고 있지만, 국내 중저가화장품 브랜드 시장의 확대로 각 브랜드 마다 경쟁이 심화되 어 새로운 마케팅 전략이 필요하게 되었다. 특히 화장품 브랜드의 공간연출에 있어서는 제품 테스트 존의 활성 여부에 따라 매출과 직결되는 특성을 가지고 있어 체험적 공간연출의 필요성은 매우 커 졌고, 그에 따라 체험 마케팅에 대한 관심이 커지게 되었다(Lee \& Lee, 2013). 전통적 마케팅이 상품의 물리적 특징과 혜택을 강조하 여 좁은 의미의 상품 범주와 경쟁 범위를 다루고 있다면, 체험 마케 팅은 상품 범주와 경쟁의 범위를 훨씬 더 폭넓게 정의하고 있으며, 고객의 이성적 판단과 감정적 요인이 존재함을 가정하고 포괄적이 고 총체적 체험을 위해서 브랜드 이름이나 로고, 매장환경, 커뮤니
케이션, 웹 사이트, 각종 이벤트 등 다양하고 다각적인 체험 제공 수단으로 사용하고 있다(Park \& Hwang, 2005).

체험은 대상과의 직접적이고 전체적인 접촉을 뜻하는 것으로 경 험을 통하여 얻어지는 일련의 과정을 의미한다. 따라서 체험은 단 순히 구경하는 것이 아니고 참여하는 것, 몸소 경험하는 것을 의미 하며, 실제로 보고, 듣고, 겪는 일 또는 그 과정에서 얻는 지식이나 기능을 총체적으로 나타내는 용어이다(Yang \& Jo, 2016).

그 동안 체험의 중요성은 여러 학자에 의해 꾸준히 연구되 어왔으며 특히 Schmitt (1999)는 전략적 체험 모듈(strategic experiential modules, $\mathrm{SEMs})$ 에 관한 연구에서 감각적 체험, 감 성적 체험, 인지적 체험, 행동적 체험, 관계적 체험을 활용하여 소 비자의 총체적인 체험을 창조할 것을 강조하고 있다(Moon et al., 2008; Moon et al., 2015). 감각 체험(sense)은 미학적 즐거움, 흥 분, 아름다움을 제공하는 것을 의미하며, 감성 체험(feel)은 즐거움, 자부심 등으로 느낌 및 감정을 제공하는 것을 말한다(Kim \& Lee, 2014; Yoon, 2015). 인지 체험(think)은 소비자의 지성에 호소하여 놀라움, 호기심, 흥미 등을 자극하는 것을 말하며 행동 체험(act)은 다른 사람과 상호작용을 통해 발생하는 결과물을 의미하고, 마지막 
으로 관계 체험(relate)은 추상적 사회집단과의 연결로서 감각, 감 성, 인지, 행동 체험을 포괄하는 개념이다(Moon et al., 2008; Kim \& Lee, 2014; Yoon, 2015).

Schmitt (1999)의 연구를 기반으로 2000년 이후 체험 마케팅 관 련 연구가 패션, 관광, 광고, 이벤트 등 문화 컨텐츠 분야(Park \& Hwang, 2005; Moon et al., 2008; Shin, 2010; Kim \& Lee, 2014; Yoon, 2015)에서 실증연구가 활발히 진행되고 있으나 다른 분야 연 구와 비교할 때 화장품 산업 분야에서 선행된 저가화장품 체험 마 케팅 관련 연구는 미비한 실정이다. 체험 제공수단과 체험 마케팅 유형에 관한 연구(Lee \& Hwang, 2010) 결과에서는, 장기적인 고 객관계 유지와 브랜드 자산을 확보하기 위한 중요수단으로 체험마 케팅이 적극적으로 활용되고 있으며 고객이 제품을 미리 써 볼 수 있다는 주도적인 느낌을 받을 수 있는 행동 마케팅을 적극 활용해 야 할 것을 제시하였다. 체험요인이 브랜드 관계에 미치는 영향에 관한 연구(Kim \& Chung, 2011)에서는 감성적 경험이 고객과 브랜 드와의 관계형성에 중요한 변인이며 감각과 감정을 자극할 수 있 는 경험 마케팅 전략이 필요하다는 것을 시사하였다. 또한, Hwang $\&$ Lee (2011)의 화장품 브랜드 숍에서의 체험마케팅 유형이 브랜드 만족, 애착 및 충성도 형성에 미치는 영향에 관한 연구 결과에서 소 비자 체험을 중심으로 체험 마케팅의 영향력을 고려하여 브랜드 만 족, 애착, 충성도를 높이기 위해 각 브랜드에 적합한 마케팅 전략을 수립해야 함을 시사하였다. 이와 같은 선행 연구의 결과로, 체험요 인이 브랜드 자산에 주요한 영향을 미칠 것이라는 예측을 할 수 있 으며 총체적 체험요인 또는 체험요인의 구성요소에 따라 브랜드와 의 관계에 미치는 영향이 다르게 나타나고 있음을 알 수 있다.

이에 본 연구의 목적은 저가화장품 매장에서 체험요인들의 총체 적 관점이 직접 체험하는 테스터 제품 사용에는 어떠한 영향을 미 치는지 분석하고자 한다. 따라서 본 연구에서는 저가화장품 브랜드 를 차별화 시켜주며 브랜드 가치 향상을 위한 요인을 테스트 제품 사용이라 보고, 다른 저가 브랜드와의 경쟁우위를 위한 수단으로 Schmitt (1999)가 제시한 감각, 감성, 인지, 행동, 관계의 전략적 체 험모듈을 활용하여 저가화장품 매장에서 나타나는 총체적 체험요 인이 테스트 제품에 미치는 만족도와의 영향관계를 규명하고자 한 다. 또한 체험요인과 브랜드간의 관련성을 재조명하고 테스터 제품 의 중요성과 이에 따른 전략적 시사점을 제공하고자 한다.

\section{Methods}

\section{1. 연구대상 및 자료수집}

본 연구대상의 표집은 2016년 1월 26일부터 2016년 3월 31일까 지 수도권 및 경기도 지역에서 저가화장품을 사용한 경험이 있는 성인여성 10 대부터 50 대까지의 연령대를 대상으로 편의 표집하였 다. 총 400 명에게 설문을 배포하여 자기 기입식으로 작성하였으며 그 중 응답이 불충분한 24 부를 제외한 설문지 총 376 부를 본 연구 의 자료로 사용하였다.

\section{2. 측정항목 및 내용}

본 연구에 사용한 문항은 인구통계학적 특성(5문항), 체험요인 (22문항), 만족도(12문항) 총 39문항으로 구성되었으며, 선행 연구 (Hwang, 2006; Moon et al., 2008; Lee \& Hwang, 2010; Hwang \& Lee, 2011; Kim \& Hwang, 2011; Yoon \& Lee, 2012)에서 사용 된 측정항목을 수정 - 보완하였다. 감각요인은 매장 내 분위기, 디 스플레이, 조명, 향기와 같은 요소를 포함하여 5 문항으로 구성하였 고, 감성요인은 즐거움, 행복감, 새로운 경험 등의 5 문항으로 구성 하였다. 인지요인으로는 호기심 자극, 브랜드에 대한 관심, 흥미와 같은 요소를 포함하여 4 문항으로 구성하였고, 브랜드와의 관계요 인은 유대감, 친근감 등 관계요인 4문항을 구성하였으며, 마지막으 로 행동요인은 다른 사람과 상호작용한 결과뿐만 아니라 라이프스 타일, 구매빈도 등의 내용을 포함하는 4 문항으로 구성하였다. 설문 지의 측정항목구성과 출처는 다음과 같다(Table 1).

\section{3. 분석방법}

본 연구의 실증분석은 모두 유의수준 $5 \%$ 에서 검증하였으며, 통 계처리는 SPSS WIN 21.0 프로그램(BM, USA)을 사용하여 분석 하였다.

1) 인구통계학적 특성을 알아보기 위하여 빈도분석(frequency analysis)을 실시하였다.

2) 저가화장품 체험요인 및 매장 방문 후 테스터 제품 사용만족도의 신뢰 도는 Cronbach's $\alpha$ 의 계수로 판단하였다.

3) 저가화장품 체험요인이 매장 방문 후 테스터 제품 사용만족도에 미치 는 영향을 알아보기 위하여 상관분석과 다중회귀분석을 실시하였다.

Table 1. Configuration of a questionnaire

\begin{tabular}{|c|c|c|c|}
\hline Research variables & Scales & No. of questions & Quotation \& applied data \\
\hline Demographic features & Nominal scale & 5 & Organization of researchers \\
\hline Experience factors & 5-point likert scale & 22 & $\begin{array}{l}\text { - Moon et al. (2008) } \\
\text { - Lee \& Hwang (2010) } \\
\text { - Hwang \& Lee (2011) } \\
\text { - Yoon \& Lee (2012) }\end{array}$ \\
\hline Satisfaction & 5-point likert scale & 12 & $\begin{array}{l}\text { - Hwang (2006) } \\
\text { - Hyun (2014) }\end{array}$ \\
\hline
\end{tabular}




\section{Results and Discussion}

\section{1. 인구통계학적 특성}

연령은 '18세 이하'가 35.9\%, '19-20세'가 49.2\%, '21세 이상'이 $14.9 \%$ 이었으며, 한달 평균 용돈은 ' 30 만원 이상' $34.0 \%$, '20-30만 원 미만' $25.5 \%, 10-20$ 만원 미만' $21.8 \%$, '10만원 미만' $18.6 \%$ 순으 로 나타났다. 한달 평균 저가 브랜드 매장 방문 횟수는 '월 2-3회' 가 $44.4 \%$ 로 가장 많았고, 이어서 '월 4-5회’ $23.1 \%$, '월 1회’ $21.5 \%$, '월 6회 이상' $10.9 \%$ 순이었으며, 매장 방문 시 1 회 평균 구입금액은 '1-5만원 미만' $64.9 \%$, '1만원 미만' $15.7 \%$, '5-10만원 미만' $14.6 \%$, '10만원 이상' $4.8 \%$ 순이었다. 매장 1 회 방문 시 평균 쇼핑 시간은
‘10-30분 미만'이 59.0\%, ‘10분 미만'이 19.9\%, ‘30분-1시간 미만'이 $11.7 \%$, '시간 이상'이 $9.3 \%$ 순으로 조사되었다(Table 2).

\section{2. 저가화장품 체험요인과 테스터 제품 사용만족도}

저가화장품 체험요인과 매장 방문 후 테스터 제품 사용만족도 순 위는 1순위로 브랜드 감각요인( $\mathrm{M}=3.49)$, 브랜드 인지요인( $\mathrm{M}=3.47)$, 브랜드 행동요인( $M=3.46)$, 브랜드 감성요인( $M=3.27)$, 브랜드 관계 요인(M=3.21) 순으로 체험요인이 높았으며, 매장 방문 후 테스터 제 품 사용만족도의 평균은 3.49 로 높게 나타났다(Table 3).

Table 2. General features

\begin{tabular}{|c|c|c|c|}
\hline & Category & Frequency $(\mathrm{N})$ & Percentage (\%) \\
\hline \multirow{3}{*}{ Age } & 18 or under & 135 & 35.9 \\
\hline & $19-20$ & 185 & 49.2 \\
\hline & 21 or over & 56 & 14.9 \\
\hline \multirow{4}{*}{ Monthly allowance } & Less than KRW 100,000 & 70 & 18.6 \\
\hline & KRW 100,000 -less than KRW 200,000 & 82 & 21.8 \\
\hline & KRW 200,000 -less than KRW 300,000 & 96 & 25.5 \\
\hline & KRW 300,000 or more & 128 & 34.0 \\
\hline \multirow{4}{*}{ Frequency of monthly visits } & Once a month & 81 & 21.5 \\
\hline & 2-3 times a month & 167 & 44.4 \\
\hline & 4-5 times a month & 87 & 23.1 \\
\hline & 6 times or more a month & 41 & 10.9 \\
\hline \multirow{4}{*}{ Amount spent per visit } & Less than KRW 10,000 & 59 & 15.7 \\
\hline & KRW 10,000-less than KRW 50,000 & 244 & 64.9 \\
\hline & KRW 50,000-less than KRW 100,000 & 55 & 14.6 \\
\hline & KRW 100,000 or more & 18 & 4.8 \\
\hline \multirow{5}{*}{ Average shopping time } & Less than $10 \mathrm{~min}$ & 75 & 19.9 \\
\hline & 10 min-less than 30 min & 222 & 59.0 \\
\hline & $30 \mathrm{~min}$-less than $1 \mathrm{~h}$ & 44 & 11.7 \\
\hline & $1 \mathrm{~h}$ or more & 35 & 9.3 \\
\hline & Total & 376 & 100.0 \\
\hline
\end{tabular}

Table 3. Low-price cosmetics experience factors and satisfaction with the test products

\begin{tabular}{|c|c|c|c|c|c|c|}
\hline Category & & $\mathrm{N}$ & Min & Max & Mean & SD \\
\hline \multirow{5}{*}{ Low-price cosmetics experience factors } & Sense & 376 & 1.00 & 5.00 & 3.49 & 0.67 \\
\hline & Feel & 376 & 1.00 & 5.00 & 3.27 & 0.72 \\
\hline & Think & 376 & 1.00 & 5.00 & 3.47 & 0.74 \\
\hline & Relate & 376 & 1.00 & 5.00 & 3.21 & 0.71 \\
\hline & Act & 376 & 1.00 & 5.00 & 3.46 & 0.71 \\
\hline Satisfaction with the test products & & 376 & 1.00 & 5.00 & 3.49 & 0.66 \\
\hline
\end{tabular}

SD, Standard deviation 


\section{3. 신뢰도 검증}

신뢰성의 측정방법은 동일한 측정도구를 동일한 대상에 시간을 달리하여 적용결과를 비교하는 검증-재검증, 항목분할 측정치의 상관도, 내적 일관성 등이 있다. 본 연구에서는 저가화장품의 체험 요인의 평가항목과 만족도의 평가항목 도구가 일관성 있게 측정되 었는지 확인하기 위해 Cronbach's $\alpha$ 계수를 사용하여 신뢰도 분석 을 실시하였다. 일반적으로 사회과학에서 Cronbach's $\alpha$ 값의 기준 은 0.6 이상 척도이면 높은 내적 일관성의 단일 차원 구성개념으로 볼 수 있다. 따라서 본 연구의 신뢰도 분석결과 0.779-0.926을 나 타내어 평가항목의 척도는 내적 일관성을 가지는 단일차원의 구성 개념인 것을 확인할 수 있어 0.6 이상을 기준으로 신뢰성을 평가하 였다(Table 4).

\section{4. 저가화장품 체험요인이 매장 방문 후 테스터 제품 사용만족 도에 미치는 영향}

저가화장품 체험요인과 매장 방문 후 테스터 제품 사용만족도와 의 상관 관계 연구 결과는 Table 5 에 나타내었다. 매장 방문 후 테 스터 제품 사용만족도는 저가화장품 체험요인의 브랜드 행동요인 $(\mathrm{r}=0.667, p<.001)$, 브랜드 관계요인( $(\mathrm{r}=0.640, p<.001)$, 브랜드 인 지요인( $\mathrm{r}=0.629, p<.001)$, 브랜드 감성요인( $(\mathrm{r}=0.598, p<.001)$, 브랜 드 감각요인(r=0.571, $p<.001)$ 순으로 높은 정 $(+)$ 의 상관 관계가 있 는 것으로 나타났다.

저가화장품 체험요인이 매장 방문 후 테스터 제품 사용만족도 에 미치는 영향을 알아보기 위하여 다중회귀분석을 실시한 결과,
$\mathrm{R}^{2}=0.579$ 로 전체 변동의 $57.9 \%$ 로 회귀모형을 설명하고 있음을 알 수 있다(Table 6). 변수간 다중공선성을 진단하기 위하여 분산팽창 계수(variable inflation factor, VIF)와 허용치(tolerance)를 살펴보 았으며, 일반적으로 분산팽창계수가 10 이상이거나 허용치가 0.1 보다 작으면 다중공선성의 문제가 있다고 판단하게 된다. 본 분석 에서 변수들의 VIF값은 모두 10 이하였고, 허용치는 0.1 보다 크게 나타나 다중공선성의 문제는 발생하지 않는 것으로 볼 수 있다. 모 형에 대한 분산분석 결과, 추정된 모형은 유의한 것을 알 수 있으 며 $(F=101.899, p<.001)$, 저가화장품 체험요인의 브랜드 행동요인 ( $\beta=0.262, p<.001)$, 브랜드 관계요인 ( $\beta=0.246, p<.001)$, 브랜드 감 각요인( $\beta=0.191, p<.001)$, 브랜드 인지요인 $(B=0.130, p<.05)$ 순으 로 매장 방문 후 테스터 제품 사용만족도에 유의미한 영향력을 미치 는 것으로 나타났다. 따라서, 저가화장품 체험요인 중 브랜드 행동요 인과 브랜드 관계요인, 브랜드 감각요인, 브랜드 인지요인이 높을수 록 매장 방문 후 테스터 제품 사용만족도가 높은 것을 알 수 있다.

\section{Conclusion}

화장품 산업의 발전으로 인하여 성숙기에 접어든 화장품 시장에 저가화장품 시장이 급격히 성장하면서 치열한 경쟁이 벌어지고 있 다. 이러한 상황에서는 단순한 제품 광고만으로 차별화하기 어렵 기 때문에 제품의 가격과 품질뿐만 아니라 소비자가 생각하는 브랜 드 가치에 대한 필요를 직접 체험하여 느낄 수 있도록 체험 마케팅

\section{Table 4. Reliability test}

\begin{tabular}{llcc}
\hline Category & & No. of questions & Cronbach's $\alpha$ \\
& Sense & 5 & 0.848 \\
Low-price cosmetics experience factors & Feel & 5 & 0.874 \\
& Think & 4 & 0.850 \\
Satisfaction with the test products & Relate & 4 & 0.868 \\
\hline
\end{tabular}

Table 5. Correlations between low-price cosmetics experience factors and satisfaction with the test products

\begin{tabular}{|c|c|c|c|c|c|c|c|}
\hline \multirow{2}{*}{ Category } & & \multicolumn{5}{|c|}{ Low-price cosmetics experience factors } & \multirow{2}{*}{$\begin{array}{l}\text { Satisfaction with the } \\
\text { test products }\end{array}$} \\
\hline & & Sense & Feel & Think & Relate & Act & \\
\hline \multirow{5}{*}{ Low-price cosmetics experience factors } & Sense & 1 & & & & & \\
\hline & Feel & $0.543^{* * *}$ & 1 & & & & \\
\hline & Think & $0.602^{* * *}$ & $0.636^{* * *}$ & 1 & & & \\
\hline & Relate & $0.460^{* * *}$ & $0.628^{* * *}$ & $0.600^{* * *}$ & 1 & & \\
\hline & Act & $0.525^{* * *}$ & $0.621^{* * *}$ & $0.677^{* * *}$ & $0.647^{* * *}$ & 1 & \\
\hline Satisfaction with test products & & $0.571^{* * *}$ & $0.598^{* * *}$ & $0.629^{* * *}$ & $0.640^{* * *}$ & $0.667^{* * *}$ & 1 \\
\hline
\end{tabular}

Data in table is $r$ value, which is Pearson correlation coefficient.

$p<.001$ 
전략이 활발하게 전개되고 있다. 따라서 본 연구에서는 저가화장품 체험요인이 제품 테스트를 통한 소비자의 만족도에 미치는 영향을 파악함으로써 저가화장품 마케팅 전략 구축방안을 제시하고자 하 였으며 결과는 다음과 같다.

첫째, 저가화장품 체험요인은 브랜드 감각요인, 인지요인, 행동 요인, 감성요인, 관계요인의 순으로 높게 나타났으며 매장 방문 후 테스터 제품 사용만족도의 평균은 3.49로 높게 나타났다. 이 연구 결과는 시각, 청각, 촉각, 후각 등을 자극하는 감각을 통하여 즐거 움과 만족을 느끼고 브랜드에 대한 긍정적인 태도를 갖게 되는 것 을 알 수 있다.

둘째, 저가화장품 체험요인이 매장방문 후 테스터 제품 사용만 족도에 미치는 영향에 있어 행동요인, 관계요인, 감각요인, 인지요 인이 높을수록 매장 방문 후 테스터 제품 사용만족도가 높은 것으 로 나타났다. 이는 체험요인이 저가화장품 매장방문 후 테스트 제 품 사용만족도 형성에 영향을 미치는 것을 알 수 있으며 총체적인 체험요인이 만족도에 작용하는 중요한 요소임을 시사한다. 또한 저 가화장품 매장 방문 소비자들이 테스터 제품을 직접 체험함으로써 자신의 라이프스타일을 변화시키고 장기적인 고객 확보와 반복구 매를 유도할 수 있으며 이러한 결과는 저가화장품 매장의 총체적 체험요인이 브랜드 체험에 있어서 테스터 제품 사용만족도에 대해 중요한 요소임을 알 수 있다. 따라서 저가화장품 매장의 차별화를 위해서는 가격, 품질 향상뿐만 아니라 매장의 분위기, 디스플레이 의 요소와 소비자의 호기심을 자극하고, 유대감을 형성하고, 즐거 움과 행복함의 감정으로 테스트 제품의 체험에 대한 만족도를 높여 재 구매를 위한 행동 마케팅요인이 중요한 변수가 되는 것을 시사 한다. 이러한 행동적 체험은 다른 사람과의 상호작용한 결과로 발 생한 체험으로 장기적 행동패턴의 새로운 기회를 제공함으로써 만 족도를 높게 하여 궁극적으로는 소비자를 더욱 강하게 자극함으로 써 저가화장품 브랜드만의 고유성과 차별성을 나타낼 수 있다. 이 처럼 체험요인을 활용한 마케팅 사례는 한 가지 요소를 활용하는 것이 아니라 총체적이고 복합적으로 연계한 새로운 서비스 마케팅
을 활용하여 소비자에게 다양한 체험이 동시에 이루어 질 수 있도 록 한다. 뿐만 아니라 단순히 TV 광고를 통해서는 브랜드 이미지를 확립하는 효과가 부족하기 때문에 소비자가 직접 보고 느끼고 경험 하는 체험요인을 활용하여 구매행동으로 이어질 수 있는 브랜드의 이미지를 심어주는 것이 중요할 것으로 사료된다.

본 연구에서는 저가화장품 매장의 총체적 체험요인과 모든 테스 터 제품에 대한 만족도를 조사하였으나 기능적 분류에 대한 세부 연구가 부족하다는 연구의 한계점이 있다. 따라서 향후 연구에서는 표본의 특성을 기초 제품, 색조 제품, 네일 제품 등으로 구체화하여 보완 연구가 진행된다면 더욱 구체적이고 일반화된 결과를 도출할 수 있을 것이며 이를 통해 제품별 체험요인에 대한 만족도를 비교 분석하여 포괄적인 연구결과를 얻을 수 있을 것으로 사료된다.

\section{References}

Hwang JS, Lee JM. The effect which cosmetic brand shop experience marketing makes on brand satisfaction, attachment and loyalty. Journal of the Korean Society of Cosmetology, 17: 1086-1096, 2011.

Hwang YS. Perceived service qualities in cosmetics purchasing, those difference and consumer satisfaction among store types. Fashion \& Textile Research Journal, 8: 449-457, 2006.

Hyun HK. Effects of festival experiential factors on festival satisfaction and behavioral intention: with focus on Muju firefly festival. The Journal of the Korea Contents Association, 14: 494-502, 2014.

Kim JH, Lee JH. The qualitative study on the customer experience of shopping centers: focused on comparison between internal and external experience elements on

\section{Table 6. Effects of low-price cosmetics experience factors on satisfaction with the test products}

\begin{tabular}{|c|c|c|c|c|c|c|c|}
\hline \multirow{2}{*}{ Category } & & \multicolumn{6}{|c|}{ Dependent variables: satisfaction with test products } \\
\hline & & B & SD & B & $\mathrm{t}$ & $p$ & VIF \\
\hline (Constant) & & 0.564 & 0.135 & & $4.189^{* * *}$ & 0.000 & \\
\hline \multirow{5}{*}{ Low-price cosmetics experience factors } & Sense & 0.189 & 0.044 & 0.191 & $4.332^{* * *}$ & 0.000 & 1.710 \\
\hline & Feel & 0.087 & 0.046 & 0.095 & 1.907 & 0.057 & 2.168 \\
\hline & Think & 0.116 & 0.047 & 0.130 & $2.463^{*}$ & 0.014 & 2.434 \\
\hline & Relate & 0.228 & 0.045 & 0.246 & $5.070^{* * *}$ & 0.000 & 2.068 \\
\hline & Act & 0.243 & 0.048 & 0.262 & $5.071^{* * *}$ & 0.000 & 2.342 \\
\hline \multicolumn{8}{|c|}{$R^{2}=0.579$, adj $R^{2}=0.574, F=101.899^{* * *}$} \\
\hline
\end{tabular}

B, Unstandardized beta; SD, Standard deviation; $\beta$, Standardized beta; $t, t$ score; VIF, Variable inflation factor; $R^{2}$, Coefficient of determination; Adj $\mathrm{R}^{2}$, Adjusted coefficient of determination ${ }^{*} p<.05,{ }^{* * *} p<.001$ 
the fashion brand stores. Korean Journal of Human Ecology, 23: 101-122, 2014.

Kim MH, Hwang CS. The difference of the satisfaction level according to the shopping orientation of cosmeceuticals: focusing on whitening, sun screen, anti-aging cosmetics. Asian Journal of Beauty and Cosmetology, 9: 153-166, 2011.

Kim SE, Chung MS. The effect of emotional experience with Korea's low-price cosmetic brands on brand relationship. The Research Journal of the Costume Culture, 19: 565578, 2011.

Lee BR, Lee JK. A study on low-priced cosmetics brand in space direction of applying the theory of marketing experience Pine \& Gilmore. Journal of Korea Institute of Spatial Design, 24: 49-58, 2013.

Lee JM, Hwang J. The effect of experiential marketing on the brand equity of low-priced cosmetics brands. Journal of the Korean Society of Costume, 60: 100-117, 2010.

Moon HK, Youn CR, Park JE, Lee YR. The effects of perceived experiential marketing activity on consumers' attitude toward apparel brands. Fashion \& Textile Research Journal, 10: 181-190, 2008.

Moon SA, Byun KI, Park SS. The effect of the elements of experiential marketing on the visitors' satisfaction, brand attitude and revisit intention: focused on Mungyeong omija festival. Tourism Research, 40: 17-43, 2015.
Park SY, Hwang JE. Effect of in-store experience on brand attitude and purchase intention. Ewha Management Review, 23: 69-93, 2005.

Schmitt B. Experiential marketing. Journal of Marketing Management, 15: 53-67, 1999.

Shin DJ. The effects of experiential factors on enjoyment, satisfaction and behavioral intention in an event: an application of Pine \& Gilmore's experience theory. Journal of Tourism Sciences, 34: 251-270, 2010.

Yang GS, Jo EJ. The structural relationship between perceived value, quality of life, and experience: an example from tourists at a Korean tea museum. International Journal of Tourism and Hospitality Research, 30: 17-30, 2016.

Yoon SM, Lee TH. Effect relationship of the experience on emotion and satisfaction in theme park: focused on the perspective of experiential marketing. Journal of Tourism and Leisure Research, 24: 289-308, 2012.

Yoon SM. The effects of tourist experience from festival on satisfaction from perspectives of experience economy (4ES) and experiential marketing (SEMs): focusing on the Seosan Haemieupseong festival. Journal of Hospitality and Tourism Studies, 17: 337-360, 2015. 


\section{국문초록}

\section{저가화장품 체험요인이 테스터 제품 사용만족도에 미치는 영향}

이상은

수원여자대학교 미용예술과, 경기도 수원시, 한국

목적: 본 연구는 저가화장품 브랜드를 차별화 시켜주는 전략적 체험모듈을 이용하여 테스트 제품에 미치는 만족도와의 영향 관계를 규명하고자 한다. 방법: 저가화장품 매장 방문경험이 있는 여성을 대상으로 편의 표집하였다. 만족도의 신뢰도는 Cronbach's $\alpha$ 계수로 판단하였고, 저가화장품 체험요인이 매장 방문 후 테스터 제품 사용만족도에 미치는 영향을 알아보기 위하 여 상관분석과 다중회귀분석을 실시하였다. 결과: 저가화장품 체험요인과 매장 방문 후 테스터 제품 사용만족도와의 상관관계는 행동요인, 관계요인, 인지요인, 감성요인, 감각요인 순으로 상관관계가 있는 것으로 나타났다. 저가화장품 체험요인에서 행동요 인과 관계요인, 감각요인, 인지요인이 높을수록 매장 방문 후 테스터 제품 사용만족도가 높은 것으로 나타났다. 결론: 체험요인을 활용한 마케팅 사례는 한 가지 요소를 활용하는 것이 아니라 총체적이고 복합적으로 연계한 새로운 서비스 마케팅을 활용하여 소 비자에게 다양한 체험을 직접 보고 느끼고 경험하게 함으로써 브랜드의 이미지를 심어주는 것이 중요할 것으로 사료된다.

핵심어: 체험 마케팅, 만족도, 저가화장품, 체험요인, 화장품 산업

\section{참고문헌}

김명희, 황춘섭. 기능성화장품 구매성향에 따른 소비자 만족도: 미백개선제, 자외선차단제, 주름개선제. 아시안뷰티화장품학 술지, 9: 153-166, 2011.

김성은, 정명선. 국내 저가 화장품 브랜드에 대한 감성적 경험이 브랜드 관계에 미치는 영향. 복식문화연구, 19: 565-578, 2011. 김정희, 이진화. 대형 쇼핑센터에서의 소비자 체험에 관한 탐색적 연구: 패션브랜드 매장 내 · 외부에서의 체험요소 비교를 중 심으로. 한국생활과학회지, 23: 101-122, 2014.

문희강, 윤초롱, 박지은, 이유리. 의류 브랜드의 체험마케팅 활동에 대한 지각이 소비자 브랜드 태도에 미치는 영향. 한국의류 산업학회지, 10: 181-190, 2008.

박성연, 황정은. 매장내 체험적 경험이 브랜드 태도 및 구매의도에 미치는 영향: 디지털 체험관을 중심으로. 경영논총, $23:$

69-93, 2005.

신동주. 이벤트에서의 체험요소가 체험즐거움, 체험만족 및 행동의도에 미치는 영향: Pine \& Gilmore의 체험이론을 중심으

로. 관광학연구, 34: 251-270, 2010.

양길승, 조은주. 체험요인에 따른 지각가치와 삶의 질과의 구조 관계: 보성 한국차박물관 관광객을 대상으로. 관광연구저널,

30: 17-30, 2016.

윤설민, 이태희. 테마파크에서의 체험이 감정과 만족도에 미치는 영향관계: 체험마케팅 관점을 중심으로. 관광레저연구, 24 :

289-308, 2012.

윤설민. 체험경제(4Es)와 체험마케팅(SEMs) 관점에 의한 축제에서의 관광객 체험이 만족도에 미치는 영향: 서산 해미읍성역

사체험축제를 중심으로. 호텔관광연구, 17: 337-360, 2015.

이보람, 이정교. Pine \& Gilmore의 체험마케팅 이론을 적용한 중저가 화장품 브랜드 공간연출에 관한연구. 한국공간디자인학

회논문집, 24: 49-58, 2013.

이정민, 황진숙. 저가 화장품 브랜드 체험 제공수단과 체험마케팅 유형이 브랜드자산에 미치는 영향. 복식, 60: 100-117, 2010.

현혜경. 축제 체험요인과 축제만족, 행동의도와의 영향관계: 무주반딧불축제를 중심으로. 한국콘텐츠학회논문지, 14: 494-

502, 2014. 
황연순. 화장품 구매시 지각된 서비스품질, 점포유형에 따른 차이와 고객만족도. 한국의류산업학회지, 8: 449-457, 2006. 황진숙, 이정민. 화장품 브랜드숍에서의 체험마케팅 유형이 브랜드 만족, 애착 및 충성도 형성에 미치는 영향. 한국미용학회 지, 17: 1086-1096, 2011. 


\section{中文摘要}

\section{低廉化妆品的体验因素对试用产品满意度的影响}

李相恩

水原女子大學校 美容艺术科，京畿道 水原市，韩国

目的: 利用低廉化妆品品牌差别化战略体验模式阐明试用产品满意度的影响关系。方法: 对访问过低廉化妆品店的成人女性 进行抽样的方式选择研究对象。满意度的可靠性通过 Cronbach's a 俦断。为了测量低廉化妆品的体验因素对试用产品满意 度的影响, 进行相关分析和多元回归分析。结果: 低廉化妆品体验因素和试用产品满意度的相关性, “行为”是最相关的, 其 次是“关系”，“意识”，“感性”和“感觉”。低廉化妆品体验因素中，随着“行为”、“关系”、“感觉”、“意识”的增加，试用产品 满意度也随之增加。结论: 认为体验因素为品牌的基础营销, 不只是利用一种因素, 而是利用与多种因素相结合的复杂型 的新的服务营销模式，为消费者提供“看”、“触摸”等体验机会，来建立品牌形象，更为重要。

关键词: 体验营销, 满意度, 低廉化妆品, 体验因素, 化妆品产业 
